\title{
Effects of different anesthetic techniques on the incidence of phantom limb pain after limb amputation: a population-based retrospective cohort study
}

\author{
Hyun-Seok Cho ${ }^{1}$, Sooyoung Kim ${ }^{1}$, Chan Sik Kim ${ }^{1}$, Ye-Jee Kim², Jong-Hyuk Lee ${ }^{1}$, and Jeong-Gill Leem ${ }^{1}$
}

'Department of Anesthesiology and Pain Medicine, Asan Medical Center, University of Ulsan College of Medicine, Seoul, Korea

${ }^{2}$ Department Clinical Epidemiology and Biostatistics, Asan Medical Center, Seoul, Korea

Received March 13, 2020

Revised May 22, 2020

Accepted May 22, 2020

Handling Editor: Young-Bok Lee

\section{Correspondence}

Jeong-Gill Leem

Department of Anesthesiology and Pain Medicine, Asan Medical Center, University of Ulsan College of Medicine, 88 Olympic-ro 43-gil, Songpa-gu, Seoul 05505, Korea

Tel: +82-2-3010-3861

Fax: +82-2-470-1363

E-mail: jgleem@amc.seoul.kr
Background: General anesthesia (GA) has been considered the anesthetic technique which most frequent leads to phantom limb pain (PLP) after a limb amputation. However, these prior reports were limited by small sample sizes. The aims of this study were to evaluate the incidence of PLP according to the various anesthetic techniques used for limb amputation and also to compare the occurrence of PLP according to amputation etiology using the Korean Health Insurance Review and Assessment Service for large-scale demographic information.

Methods: The claims of patients who underwent limb amputation were reviewed by analyzing the codes used to classify standardized medical behaviors. The patients were categorized into three groups-GA, neuraxial anesthesia (NA), and peripheral nerve block (PNB)-in accordance with the anesthetic technique. The recorded diagnosis was confirmed using the diagnostic codes for PLP registered within one year after the limb amputation.

Results: Finally, 7,613 individuals were analyzed. According to the recorded diagnoses, 362 patients (4.8\%) developed PLP after amputation. Among the 2,992 patients exposed to GA, 191 (6.4\%) were diagnosed with PLP, whereas 121 (4.3\%) of the 2,840 patients anesthetized with NA, and $50(2.8 \%)$ of the 1,781 patients anesthetized under PNB developed PLP. The relative risks were 0.67 (95\% confidence interval $[\mathrm{Cl}$ ], 0.53-0.84; $P<0.001)$ for NA and $0.43(95 \% \mathrm{Cl}, 0.32-0.59 ; P<$ 0.001) for PNB.

Conclusions: In this retrospective cohort study, using large-scale population-based databases, the incidence rates of PLP after limb amputations were, in the order of frequency, GA, NA, and PNB.

Key Words: Amputation; Amputees; Anesthesia; Chronic Pain; Incidence; Nerve Block; Neuralgia; Phantom Limb; Retrospective Studies.

\section{INTRODUCTION}

The loss of a body part can lead to pain and other sensations that fall into three distinct descriptive categories, namely phantom sensations, phantom pain, and residual pain. Phantom sensations are defined as pain-free perceptions emanating from the lost body part after deafferentation, and phantom pain is a painful or unpleasant sensation in the distribution of the lost or deafferented body part [1]. Phantom sensations can be a different expression (c) This is an open-access article distributed under the terms of the Creative Commons Attribution Non-Commercial License (http://creativecommons.org/licenses/by-nc/4.0/), which permits unrestricted non-commercial use, distribution, and reproduction in any medium, provided the original work is properly cited.

(c) The Korean Pain Society, 2020
Author contributions: Hyun-Seok Cho: Writing/manuscript preparation; Sooyoung Kim: Writing/manuscript preparation; Chan Sik Kim: Writing/ manuscript preparation; Ye-Jee Kim: Formal analysis; Jong-Hyuk Lee: Methodology; Jeong-Gill Leem: Supervision. 
of phantom pain and interfere with rehabilitation therapy by enhancing and interacting with phantom pain [2-4].

Although phantom limb pain (PLP) can occur in up to $85 \%$ of patients after a limb amputation [5], its reported prevalence varies widely [6-8]. PLP is common in the first six months after surgery $[9,10]$. Although many previous studies have reported risk factors for PLP, such as preamputation pain, cause of amputation, prosthesis use, and perioperative analgesia, the exact causes remain unknown [10-12]. Although questions still surround the underlying mechanisms of PLP, there seems to be a solid theoretical basis for the role of peripheral mechanisms as well as central neural mechanisms $[13,14]$.

Only a few studies to date have evaluated the effects of anesthetic techniques on the occurrence of PLP. In two such reports, marked increases in PLP were observed soon after amputation surgery performed under general anesthesia (GA) $[15,16]$. By preventing the establishment of central sensitization, epidural anesthesia and peripheral nerve block (PNB) were observed to help with pain reduction in the first week after surgery [16]. However, these previous studies were limited by small sample sizes. Therefore, the aims of our current study were to (1) evaluate the incidence of PLP in accordance with the various anesthetic techniques used for limb amputation and (2) compare the occurrence of PLP according to amputation etiology using the Korean Health Insurance Review and Assessment Service (HIRA) database.

\section{MATERIALS AND METHODS}

This study was exempt from review by the Institutional Review Board of Asan Medical Center (protocol number 2016-0101). Our present retrospective cohort study was performed by investigating the HIRA claims of patients who underwent a limb amputation by accessing the codes used to classify standardized medical behaviors in Korea. The HIRA system provides large-scale healthcare databases including medical claims, drug utilization reviews, and medical fee verifications since 1977 [17].

Amputation surgeries (N0572 [thigh], N0573 [upper arm, forearm, lower leg], N0574 [hand, foot], and N0575 [finger, toe]) conducted between July 1, 2011 and June 30, 2015 were included. The identified patients were then categorized into three groups by the anesthetic technique used in the amputation procedure: GA, neuraxial anesthesia (NA), and PNB. Diagnosis was confirmed using diagnostic codes registered within one year after the limb amputation. Two codes-G54.6 (phantom limb syndrome with pain) and G54.7 (phantom limb syndrome without pain) from the Korean Classification of Disease, sixth edition
(KCD-6), which is a modified version of the International Classification of Disease, were included.

Demographic data (age and sex) for the study patients were collected. The etiology identified by the KCD- 6 codes for each patient was also extracted and assessed. The time periods of assessment for diabetes mellitus (DM) and the other etiologies were one year and 90 days, respectively, prior to the index date.

Baseline characteristics are presented as numbers with percentages for categorical variables. Incidence rates (IRs) per 100 person-years (PYs) and 95\% confidence intervals (CIs) of the PLP, for each of the anesthesia groups, were calculated assuming a Poisson distribution. The incidence of PLP in the GA group was compared with the incidence of PLP in both the NA and PNB groups. A Cox proportional hazard analysis was used to evaluate the association between the anesthesia group and PLP. The proportional hazards assumption was checked by examining log-log plots of the hazard functions for each anesthesia group. All statistical analyses were performed using SAS Enterprise Guide software ver. 6.1 (SAS Institute, Cary, NC).

\section{RESULTS}

During the 4-year current study period (2012-2015), 10,806 individuals aged $\geq 20$ years old were enrolled. Finally, 7,613 subjects were included in this study (Fig. 1). The baseline characteristics of the included patients are listed in Table $\mathbf{1 .}$ PLP was more common when the limb was amputated in a more proximal site (Table 2).

The incidences of PLP after amputation according to the anesthetic technique are presented in Table 3. Based on the recorded diagnoses, 362 patients $(4.8 \%)$ developed PLP after amputation. The average IR for PLP was 5.23 per 100 PY. The IR for PLP was highest in the GA group. Compared with GA, the relative risks (RRs) were 0.67 (95\% CI, 0.53-0.84; $P<0.001$ ) for NA and 0.43 (95\% CI, 0.32-0.59; $P<$ 0.001 ) for PNB (Fig. 2).

The IRs and RRs for PLP after amputation according to etiology (KCD-6 code) are presented in Table 4. The RR of the groups with DM (adjusted RR and 95\% CI, 0.50, 0.39-0.63; $P<0.001$ ) was significantly lower compared with that in patients without DM. The IR in patients with traumatic amputation was 6.05 per $100 \mathrm{PY}$, and these cases had a significantly higher RR (adjusted RR and 95\% CI, 1.85, $1.38-2.47 ; P<0.001)$ than patients without traumatic amputation. 


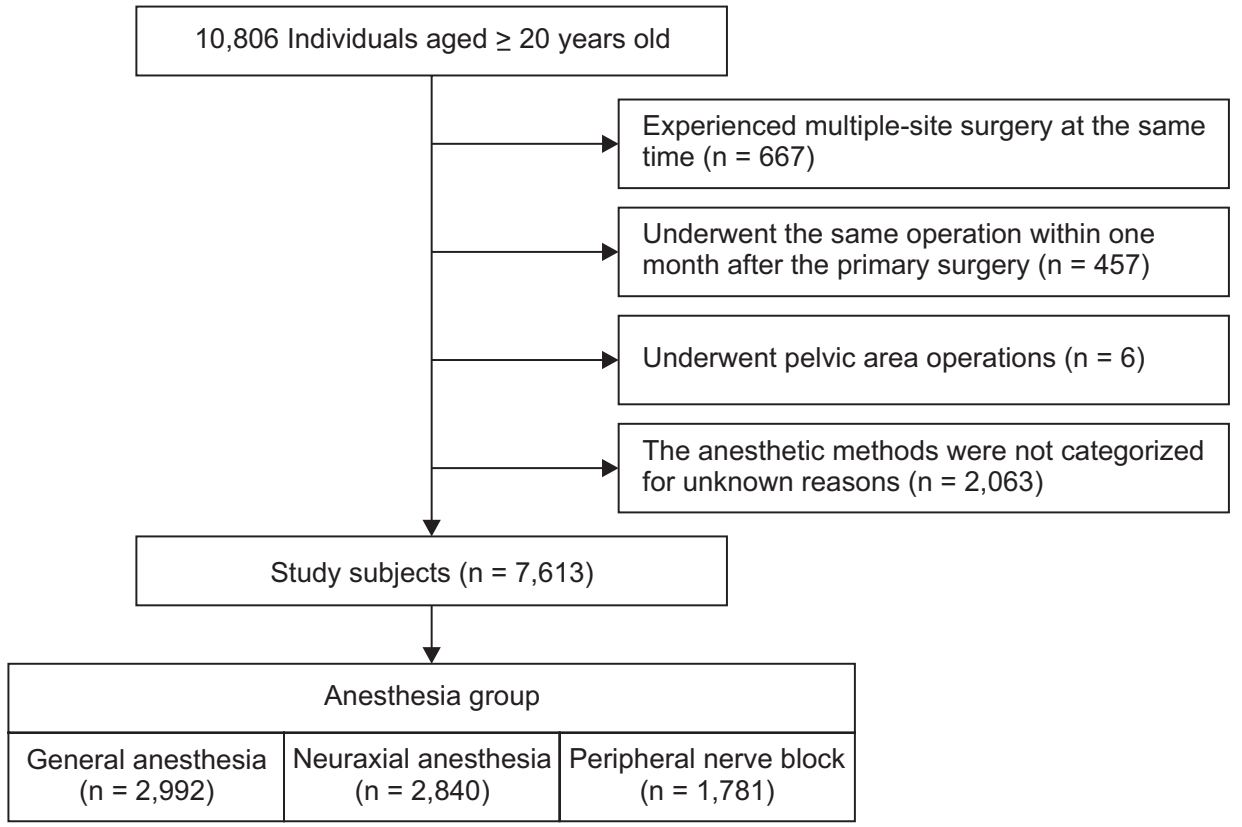

Fig. 1. Flow diagram of study enrollment. Of the 10,806 enrolled subjects, 7,613 patients were included and divided into three anesthetic groups.

Table 1. Basic Characteristics of the Study Patients Who Underwent Limb Amputation

\begin{tabular}{|c|c|c|c|c|c|}
\hline Characteristic & $\mathrm{GA}(\mathrm{n}=2,992)$ & $N A(n=2,840)$ & PNB $(n=1,781)$ & Total $(n=7,613)$ & $P$ value \\
\hline \multicolumn{6}{|l|}{ Region of amputation } \\
\hline Thigh & $338(11.3)$ & $160(5.6)$ & $3(0.2)$ & $501(6.6)$ & $<0.001$ \\
\hline Upper arm, forearm, lower leg & $741(24.8)$ & $609(21.4)$ & $40(2.2)$ & $1,390(18.3)$ & \\
\hline Hand, foot & $364(12.2)$ & 436 ( 15.4) & $128(7.2)$ & $928(12.2)$ & \\
\hline Finger, toe & $1,549(51.8)$ & $1,635(57.6)$ & $1,610(90.4)$ & $4,794(63.0)$ & \\
\hline \multicolumn{6}{|l|}{ Sex } \\
\hline Male & 2,141 (71.6) & 2,131 (75.0) & $1,312(73.7)$ & $5,584(73.3)$ & 0.010 \\
\hline Female & 851 (28.4) & 709 (25.0) & $469(26.3)$ & $2,029(26.7)$ & \\
\hline \multicolumn{6}{|l|}{ Age group (yr) } \\
\hline $20-29$ & $52(1.7)$ & $18(0.6)$ & $53(3.0)$ & $123(1.6)$ & $<0.001$ \\
\hline $30-39$ & $140(4.7)$ & $60(2.1)$ & $102(5.7)$ & $302(4.0)$ & \\
\hline $40-49$ & $370(12.4)$ & $242(8.5)$ & $240(13.5)$ & $852(11.2)$ & \\
\hline $50-59$ & $658(22.0)$ & $599(21.1)$ & $443(24.9)$ & $1,700(22.3)$ & \\
\hline $60-69$ & $712(23.8)$ & $696(24.5)$ & $417(23.4)$ & $1,825(24.0)$ & \\
\hline $70-79$ & $750(25.1)$ & $854(30.1)$ & $396(22.2)$ & $2,000(26.3)$ & \\
\hline$\geq 80$ & $310(10.4)$ & 371 (13.1) & $130(7.3)$ & $811(10.7)$ & \\
\hline
\end{tabular}

Values are presented as number (proportion).

$P$ value was estimated by chi-square test for categorical variables.

GA: general anesthesia, NA: neuraxial anesthesia, PNB: peripheral nerve block.

Table 2. Recorded Phantom Limb Pain according to Amputated Site

\begin{tabular}{|c|c|c|c|c|c|c|c|c|c|c|c|}
\hline Region of amputation & $\begin{array}{c}\text { Total } \\
\text { patients }\end{array}$ & $\begin{array}{c}\text { Event } \\
\text { patients }\end{array}$ & $\begin{array}{c}\text { Sum of } \\
\text { person- } \\
\text { years }\end{array}$ & IR & $95 \% \mathrm{Cl}$ & $\mathrm{RR}$ & $95 \% \mathrm{Cl}$ & $P$ value & $\begin{array}{c}\text { Adjusted } \\
\text { RR }\end{array}$ & $95 \% \mathrm{Cl}$ & $P$ value \\
\hline Total & 7,613 & $362(4.8)$ & $6,925.5$ & 5.23 & $4.70-5.79$ & - & - & - & - & - & - \\
\hline Thigh & 501 & $80(16.0)$ & 428.0 & 18.69 & $14.82-23.26$ & 9.22 & $6.81-12.50$ & $<0.001$ & 13.47 & $9.12-19.89$ & $<0.001$ \\
\hline Upper arm, forearm, lower leg & 1,390 & $162(11.7)$ & $1,223.0$ & 13.25 & $11.28-15.45$ & 6.63 & $5.11-8.60$ & $<0.001$ & 9.06 & $6.44-12.74$ & $<0.001$ \\
\hline Hand, foot & 928 & $33(3.6)$ & 827.8 & 3.99 & $2.74-5.60$ & 2.00 & $1.34-2.98$ & $<0.001$ & 2.36 & $1.45-3.83$ & $<0.001$ \\
\hline Finger, toe & 4,794 & $87(1.8)$ & $4,446.7$ & 1.96 & $1.57-2.41$ & 1.00 & - & - & 1.00 & - & - \\
\hline
\end{tabular}

Values are presented as number (proportion). IR expressed as 100 person-years, and $95 \% \mathrm{Cl}$ were assuming an exact Poisson distribution. Adjusted for age, sex, and anesthesia.

IR: incidence rate, Cl: confidence interval, RR: relative risk, -: not available. 
Table 3. Effects of Anesthesia on Recorded Phantom Limb Pain after Amputation

\begin{tabular}{ccccccccc}
\hline Exposure & Total patients & Event patients & Sum of person-years & IR & $95 \% \mathrm{Cl}$ & $\mathrm{RR}$ & $95 \% \mathrm{Cl}$ & $P$ value \\
\hline Total & 7,613 & $362(4.8)$ & $6,925.5$ & 5.23 & $4.70-5.79$ & - & - & - \\
GA & 2,992 & $191(6.4)$ & $2,705.9$ & 7.06 & $6.09-8.13$ & 1.00 & - \\
NA & 2,840 & $121(4.3)$ & $2,552.0$ & 4.74 & $3.93-5.67$ & 0.67 & $0.53-0.84$ & $<0.001$ \\
PNB & 1,781 & $50(2.8)$ & $1,667.6$ & 3.00 & $2.23-3.95$ & 0.43 & $0.32-0.59$ & $<0.001$ \\
\hline
\end{tabular}

Values are presented as number (proportion). IR expressed as 100 person-years, and $95 \% \mathrm{Cl}$ were assuming an exact Poisson distribution.

IR: incidence rate, Cl: confidence interval, RR: relative risk, GA: general anesthesia, NA: neuraxial anesthesia, PNB: peripheral nerve block, -: not available.

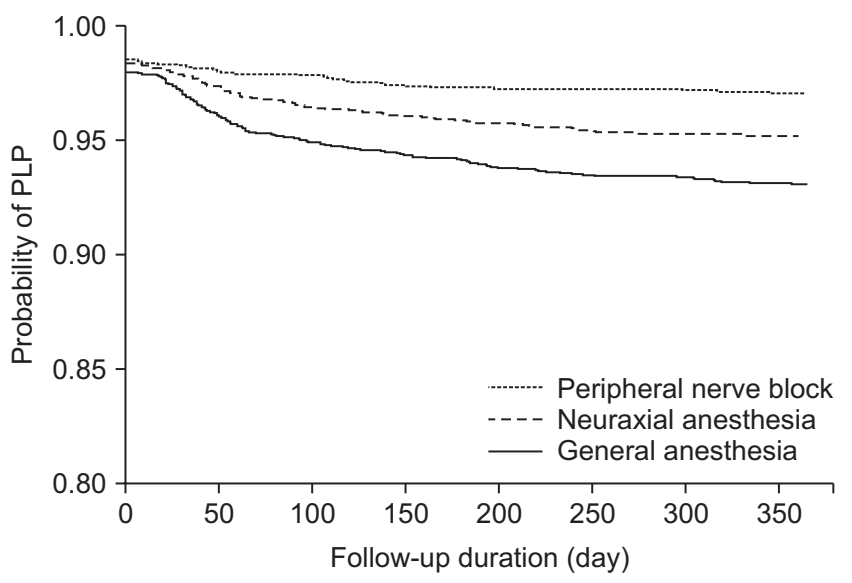

Fig. 2. Kaplan-Meier curve estimates of the effects of different anesthesia approaches on the incidence of phantom limb pain (PLP) after amputation. Compared with the general anesthesia group, amputees who had undergone neuraxial anesthesia and peripheral nerve block during the surgery have lower probabilities of PLP (log-rank test, $P<0.001$ for all comparisons).

\section{DISCUSSION}

Our current study represents the largest population-based analysis, using the HIRA database, of the relationship between anesthetic methods for amputation and PLP. There is little evidence in the current literature from communitybased research on the incidence of PLP $[18,19]$. To the best of our knowledge, ours is the first community-based study on PLP incidence.

In our present analysis, the overall IR of recorded PLP within one year after limb amputation was 5.23 per $100 \mathrm{PY}$. As reported previously, PLP was more common when the limb was amputated at a proximal site [8]. Our comparison of the various anesthetic techniques used for amputation revealed that PLP developed significantly more frequently in the GA group. Based on the etiology of PLP after limb amputation, DM and traumatic amputation significantly decreased and increased, respectively, the RR of PLP.

In our analysis of recorded diagnoses on the HIRA system, the IRs of PLP from various anesthetic techniques occupied the same order as described in previous studies, i.e., GA, NA, and PNB $[15,16]$. Thus, PNB seems to be the best anesthetic method for attenuating PLP after amputation. Because the surgical neurogenic inflammatory response may provide a source of nociceptive input into the central nervous system for a prolonged period, and the establishment of central sensitization cannot be prevented through the continuous effect of postoperative local anesthetics such as NA and PNB, GA had been considered to result in higher incidence of PLP after amputation [16]. In addition, another reason for the presumably higher incidence of PLP after GA is that patients with more compromised lesions are likely to complain of more severe pain and therefore require GA. Some patients may also be more sensitive to pain and may choose to undergo GA during amputation because of anxiety [20].

The total IRs in the present study were slightly lower than those in other recent studies [5-8]. Because PLP can emerge several years after amputation [21], the 1-year period of the present analysis could lower the IR of PLP. However, 50\% of amputees describe PLP within the first 24 hours after the surgery, and PLP manifested in less than $10 \%$ of cases one year after the amputation [21]. In addition, the two peak periods of onset were within the first month and first year after amputation [22]. Therefore, the 1-year analysis period may have had little effect on the results.

Traditionally, patients who undergo a DM-related amputation are thought to have little chance of PLP because all sensations perceived from the lower limbs are reduced by longstanding DM-related peripheral neuropathy $[23,24]$. Although a recent study has suggested no large differences in the prevalence, characteristics, or intensity of PLP among amputees based on the presence of diabetes [25], that investigation was limited by its small sample size. Our present study findings have indicated that DM lowers the occurrence of PLP in amputees. However, it should be noted that there was no detailed information on diabetes, such as duration and severity, in the database. In addition, if the IRs of PLP according to amputated sites were higher in the proximal part than the distal part, we speculated that the correlation with DM could have been because the limb amputations caused by DM are most frequently in the distal parts such as the digit (toe) or foot. 
Table 4. Effects of Amputation Etiology on Recorded Phantom Limb Pain after Amputation

\begin{tabular}{|c|c|c|c|c|c|c|c|c|c|c|c|}
\hline Etiology (KCD-6) & $\begin{array}{c}\text { Total } \\
\text { patients }\end{array}$ & $\begin{array}{c}\text { Event } \\
\text { patients }\end{array}$ & $\begin{array}{c}\text { Sum of } \\
\text { person- } \\
\text { years }\end{array}$ & IR & $95 \% \mathrm{Cl}$ & $\mathrm{RR}$ & $95 \% \mathrm{Cl}$ & $P$ value & $\begin{array}{c}\text { Adjusted } \\
\text { RR }\end{array}$ & $95 \% \mathrm{Cl}$ & $P$ value \\
\hline \multicolumn{12}{|l|}{ Diabetes mellitus } \\
\hline No & 4,344 & $260(6.0)$ & $3,991.4$ & 6.51 & $5.75-7.36$ & 1.00 & - & - & - & - & - \\
\hline Yes & 3,269 & $102(3.1)$ & $2,934.1$ & 3.48 & $2.83-4.22$ & 0.52 & $0.42-0.66$ & $<0.001$ & 0.50 & $0.39-0.63$ & $<0.001$ \\
\hline \multicolumn{12}{|c|}{ Peripheral vascular disease } \\
\hline No & 6,355 & $290(4.6)$ & $5,810.0$ & 4.99 & $4.43-5.60$ & 1.00 & - & - & - & - & - \\
\hline Yes & 1,258 & $72(5.7)$ & $1,115.5$ & 6.45 & $5.05-8.13$ & 1.27 & $0.98-1.65$ & 0.667 & 1.22 & $0.94-1.59$ & 0.137 \\
\hline \multicolumn{12}{|l|}{ Malignant neoplasm } \\
\hline No & 7,424 & 347 (4.7) & $6,753.7$ & 5.14 & $4.61-5.71$ & 1.00 & - & - & - & - & - \\
\hline Yes & 189 & $15(7.9)$ & 171.8 & 8.73 & $4.89-14.40$ & 1.71 & $1.02-2.86$ & 0.043 & 1.19 & $0.66-1.90$ & 0.680 \\
\hline \multicolumn{12}{|l|}{ Traumatic amputation } \\
\hline No & 6,294 & $287(4.6)$ & $5,685.9$ & 5.05 & $4.48-5.67$ & 1.00 & - & - & - & - & - \\
\hline Yes & 1,319 & 75 (5.7) & $1,239.6$ & 6.05 & $4.76-7.58$ & 1.23 & $0.95-1.59$ & 0.111 & 1.85 & $1.38-2.47$ & $<0.001$ \\
\hline
\end{tabular}

Values are presented as number (proportion). IR expressed as 100 person-years, and 95\% Cl were assuming an exact Poisson distribution. Adjusted for age, sex, amputation site and anesthesia.

KCD: Korean Classification of Disease, IR: incidence rate, Cl: confidence interval, RR: relative risk, -: not available.

Several studies have examined the relationship between traumatic amputation and PLP [26,27]. The incidence of PLP after traumatic amputation in children, as well as in adults, has also been presented [28]. In our present study, a significantly higher adjusted RR was observed in patients with traumatic amputation. Previous studies have suggested psychosocial variables such as post-traumatic stress disorder, depression, and anxiety as risk factors for postamputation pain $[26,29]$. In a study examining cortical somatotopic maps between patients with congenital limb atrophy and traumatic amputees, cortical reorganizaion was identified in traumatic amputees with PLP [30].

Few studies to date have examined PLP in amputees with cancer. PLP was previously found to be highly prevalent in patients with cancer who underwent a limb amputation [31]. In our present study, a significantly higher RR was observed in patients with malignant neoplasms, but adjusted RR was not significant. We had insufficient information on these cases, such as cancer stage and the presence of other therapies such as chemotherapy and radiotherapy, as well as the presence of preoperative pain. Especially in pediatric oncology, since several studies have suggested that neuropathy associated with chemotherapy can affect the development of PLP [32,33], it would be meaningful to further investigate the database related to chemotherapy. However, examining the prescription code of each anticancer drug is considered to have limitations when the periods of amputation and chemotherapy overlap. In addition, it is difficult to examine the interactions of numerous drugs with different mechanisms depending on the type of malignant neoplasm.

Several limitations in addition to those already mentioned should be noted. Our current study depended entirely on the information registered in the HIRA. If a PLP code is not added to claims data for PLP patients, the IR will be lower. Moreover, other treatment methods have been used [34]. Some Korean amputation patients may also have insisted on oriental herbal treatment only, and therefore would not have been captured in the HIRA statistics. In addition, the IR would decrease if amputees with PLP do not visit a hospital. This is a prominent limitation of this study because such factors may have influenced the relatively low incidence of PLP compared to that in other studies.

Another notable limitation of our present report is associated with the imperfect information on perioperative analgesia in HIRA. In addition, there is no information in this database on pain features or pain intensity such as a numeric rating scale or visual analogue scale. The effect of preamputation pain on the development of postoperative PLP has been discussed over the years, with several research findings demonstrating that the presence of preamputation pain increased the risk of PLP [35-37]. Optimized perioperative analgesia using epidural analgesia and/or intravenous patient-controlled analgesia commencing 48 hours preoperatively and continuing for 48 hours postoperatively has been found to decrease PLP at six months [12]. Moreover, a lumbar epidural blockade with bupivacaine and morphine for 72 hours preoperatively decreases the incidence of PLP in the first postoperative year [38]. In addition, given that higher levels of pain either before or soon after amputation might lead to chronic pain [11], the lack of information on the presence and intensity of preamputation pain should be a concern.

Furthermore, we did not prospectively stratify the different anesthetic methods by body part, and the incidence of GA could be higher because NA or PNB cannot be used for certain limb amputations. In consideration of these 


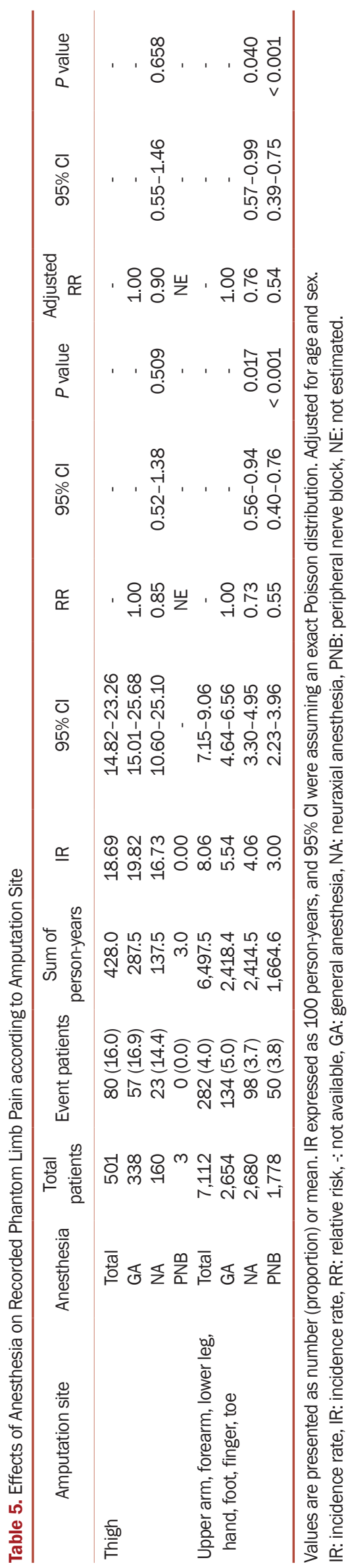

limitations, after dividing the amputation sites into thigh, where PNB was hardly performed, and other parts, the IR of the PLP according to the anesthetic methods is presented in Table 5. Because it is difficult to use regional anesthesia for areas close to the trunk, future prospective studies of PLP in distal limb amputees would be valuable.

The methodology of this study enabled us to efficiently use time and cost, based on large-scale demographic information. Despite the advantages of this research methodology, it has definite limitations as mentioned above. Because this approach is fundamentally dependent on diagnosis codes, the true incidence of a disorder cannot be evaluated using the retrospective design that we adopted in our present study. Hence, our current findings should be interpreted with caution.

In conclusion, the incidence of PLP was the highest in amputees who underwent GA during the procedure in this retrospective cohort study. Our current findings suggest that both NA and PNB can be more advantageous than GA for reducing the occurrence of PLP. These results suggest that perioperative pain control plays an important role in the development of PLP. According to the amputation etiology of recorded PLP, DM and traumatic amputation significantly decrease and increase, respectively, the incidence. However, the HIRA database in Korea provides limited information on these patients. A large-scale prospective randomized trial is required to validate the efficacy of PNB in reducing PLP.

\section{ACKNOWLEDGEMENTS}

We thank the Korean Health Insurance Review and Assessment Service for providing the insurance claims data.

\section{CONFLICT OF INTERST}

No potential conflict of interest relevant to this article was reported.

\section{FUNDING}

No funding to declare.

\section{ORCID}

Hyun-Seok Cho, https://orcid.org/0000-0002-9952-0019

Sooyoung Kim, https://orcid.org/0000-0002-7217-833X

Chan Sik Kim, https://orcid.org/0000-0002-5038-0203 
Ye-Jee Kim, https://orcid.org/0000-0002-3307-2970

Jong-Hyuk Lee, https://orcid.org/0000-0003-0952-3900

Jeong-Gill Leem, https://orcid.org/0000-0002-6899-5636

\section{REFERENCES}

1. Hsu E, Cohen SP. Postamputation pain: epidemiology, mechanisms, and treatment. J Pain Res 2013; 6: 121-36.

2. Kawashima N, Mita T, Yoshikawa M. Inter-individual difference in the effect of mirror reflection-induced visual feedback on phantom limb awareness in forearm amputees. PLoS One 2013; 8: e69324.

3. Nardone R, Langthaler PB, Höller Y, Bathke A, Frey VN, Brigo $\mathrm{F}$, et al. Modulation of non-painful phantom sensation in subjects with spinal cord injury by means of rTMS. Brain Res Bull 2015; 118: 82-6.

4. Wilkins KL, McGrath PJ, Finley GA, Katz J. Prospective diary study of nonpainful and painful phantom sensations in a preselected sample of child and adolescent amputees reporting phantom limbs. Clin J Pain 2004; 20: 293-301.

5. Sherman RA, Sherman CJ. Prevalence and characteristics of chronic phantom limb pain among American veterans. Results of a trial survey. Am J Phys Med 1983; 62: 227-38.

6. Sherman RA, Sherman CJ, Parker L. Chronic phantom and stump pain among American veterans: results of a survey. Pain 1984; 18: 83-95.

7. Davis RW. Phantom sensation, phantom pain, and stump pain. Arch Phys Med Rehabil 1993; 74: 79-91.

8. Dijkstra PU, Geertzen JH, Stewart R, van der Schans CP. Phantom pain and risk factors: a multivariate analysis. J Pain Symptom Manage 2002; 24: 578-85.

9. Montoya P, Larbig W, Grulke N, Flor H, Taub E, Birbaumer $\mathrm{N}$. The relationship of phantom limb pain to other phantom limb phenomena in upper extremity amputees. Pain 1997; 72: 87-93.

10. Kooijman CM, Dijkstra PU, Geertzen JH, Elzinga A, van der Schans CP. Phantom pain and phantom sensations in upper limb amputees: an epidemiological study. Pain 2000; 87: 33 41.

11. Hanley MA, Jensen MP, Smith DG, Ehde DM, Edwards WT, Robinson LR. Preamputation pain and acute pain predict chronic pain after lower extremity amputation. J Pain 2007; 8: 102-9.

12. Karanikolas M, Aretha D, Tsolakis I, Monantera G, Kiekkas $\mathrm{P}$, Papadoulas S, et al. Optimized perioperative analgesia reduces chronic phantom limb pain intensity, prevalence, and frequency: a prospective, randomized, clinical trial. Anesthesiology 2011; 114: 1144-54.

13. Yarnitsky D, Barron SA, Bental E. Disappearance of phantom pain after focal brain infarction. Pain 1988; 32: 285-7.

14. Flor H, Nikolajsen L, Staehelin Jensen T. Phantom limb pain: a case of maladaptive CNS plasticity? Nat Rev Neurosci 2006; 7: 873-81.

15. Ong BY, Arneja A, Ong EW. Effects of anesthesia on pain after lower-limb amputation. J Clin Anesth 2006; 18: 600-4.

16. Sahin SH, Colak A, Arar C, Tutunculer E, Sut N, Yılmaz B, et al. A retrospective trial comparing the effects of different anesthetic techniques on phantom pain after lower limb amputation. Curr Ther Res Clin Exp 2011; 72: 127-37.

17. Jang MJ, Bang SM, Oh D. Incidence of venous thromboembolism in Korea: from the Health Insurance Review and Assessment Service database. J Thromb Haemost 2011; 9: 85-91.

18. Hall GC, Morant SV, Carroll D, Gabriel ZL, McQuay HJ. An observational descriptive study of the epidemiology and treatment of neuropathic pain in a UK general population. BMC Fam Pract 2013; 14: 28.

19. Pisansky AJB, Brovman EY, Kuo C, Kaye AD, Urman RD. Perioperative outcomes after regional versus general anesthesia for above the knee amputations. Ann Vasc Surg 2018; 48: 53-66.

20. Raichle KA, Osborne TL, Jensen MP, Ehde DM, Smith DG, Robinson LR. Preoperative state anxiety, acute postoperative pain, and analgesic use in persons undergoing lower limb amputation. Clin J Pain 2015; 31: 699-706.

21. Wolff A, Vanduynhoven E, van Kleef M, Huygen F, Pope JE, Mekhail N. 21. Phantom pain. Pain Pract 2011; 11: 403-13.

22. Schley MT, Wilms P, Toepfner S, Schaller HP, Schmelz M, Konrad CJ, et al. Painful and nonpainful phantom and stump sensations in acute traumatic amputees. J Trauma 2008; 65: 858-64.

23. Benzon HT, Rathmell JP, Wu CL, Turk DC, Argoff CE. Raj's practical management of pain. 4th ed. Philadelphia, MosbyElsevier. 2008.

24. Bloomquist T. Amputation and phantom limb pain: a painprevention model. AANA J 2001; 69: 211-7.

25. Clark RL, Bowling FL, Jepson F, Rajbhandari S. Phantom limb pain after amputation in diabetic patients does not differ from that after amputation in nondiabetic patients. Pain 2013; 154: 729-32.

26. Buchheit T, Van de Ven T, Hsia HL, McDuffie M, MacLeod DB, White W, et al. Pain phenotypes and associated clinical risk factors following traumatic amputation: results from Veterans Integrated Pain Evaluation Research (VIPER). Pain Med 2016; 17: 149-61.

27. Esfandiari E, Yavari A, Karimi A, Masoumi M, Soroush M, Saeedi H. Long-term symptoms and function after war-related lower limb amputation: a national cross-sectional study. Acta Orthop Traumatol Turc 2018; 52: 348-51.

28. Ahmad J, Gupta AK, Sharma VP, Kumar D, Yadav G, Singh S. Traumatic amputations in children and adolescents: a demographic study from a tertiary care center in Northern India. J Pediatr Rehabil Med 2016; 9: 265-9.

29. Hinrichs-Rocker A, Schulz K, Järvinen I, Lefering R, Simans- 
ki C, Neugebauer EA. Psychosocial predictors and correlates for chronic post-surgical pain (CPSP) - a systematic review. Eur J Pain 2009; 13: 719-30.

30. Montoya P, Ritter K, Huse E, Larbig W, Braun C, Töpfner S, et al. The cortical somatotopic map and phantom phenomena in subjects with congenital limb atrophy and traumatic amputees with phantom limb pain. Eur J Neurosci 1998; 10: 1095-102.

31. Probstner D, Thuler LC, Ishikawa NM, Alvarenga RM. Phantom limb phenomena in cancer amputees. Pain Pract 2010; 10: 249-56.

32. DeMoss P, Ramsey LH, Karlson CW. Phantom limb pain in pediatric oncology. Front Neurol 2018; 9: 219.

33. Smith J, Thompson JM. Phantom limb pain and chemotherapy in pediatric amputees. Mayo Clin Proc 1995; 70: 357-64.

34. Kim SY, Kim YY. Mirror therapy for phantom limb pain. Ko- rean J Pain 2012; 25: 272-4.

35. Jensen TS, Krebs B, Nielsen J, Rasmussen P. Phantom limb, phantom pain and stump pain in amputees during the first 6 months following limb amputation. Pain 1983; 17: 243-56.

36. Jensen TS, Krebs B, Nielsen J, Rasmussen P. Immediate and long-term phantom limb pain in amputees: incidence, clinical characteristics and relationship to pre-amputation limb pain. Pain 1985; 21: 267-78.

37. Nikolajsen L, Ilkjaer S, Krøner K, Christensen JH, Jensen TS. The influence of preamputation pain on postamputation stump and phantom pain. Pain 1997; 72: 393-405.

38. Bach S, Noreng MF, Tjéllden NU. Phantom limb pain in amputees during the first 12 months following limb amputation, after preoperative lumbar epidural blockade. Pain 1988; 33: 297-301. 